\title{
Correction: Chatterjee, A.; et al. Transition Metal Hollow Nanocages as Promising Cathodes for the Long-Term Cyclability of $\mathrm{Li}-\mathrm{O}_{2}$ Batteries. Nanomaterials 2018, 8, 308
}

\author{
Amrita Chatterjee ${ }^{1}\left(\mathbb{D}\right.$, Siu Wing Or ${ }^{1, *(1)}$ and Yulin Cao ${ }^{1,2}$ \\ 1 Department of Electrical Engineering, The Hong Kong Polytechnic University, Hung Hom, Kowloon, \\ Hong Kong; amrita.chatterjee@polyu.edu.hk (A.C.); caoyulin@szpt.edu.cn (Y.C.) \\ 2 Physics Laboratory, Industrial Training Center, Shenzhen Polytechnic, Shenzhen 518055, China \\ * Correspondence: eeswor@polyu.edu.hk; Tel.: +852-34003345
}

Received: 4 September 2018; Accepted: 18 September 2018; Published: 20 September 2018

The authors wish to add the following information to this paper [1].

The last paragraph of Section 1 in the Introduction has been replaced by the following two paragraphs:

One of the drawbacks of using these spinel structured oxides is their low surface area [12]. In our previous work [16], we have announced the preliminary results and initial observations on the basic morphology and magnetism of a highly porous spinel-type, $\mathrm{Mn}_{3} \mathrm{O}_{4}$, called $\mathrm{Mn}_{3} \mathrm{O}_{4}$ hollow nanocages (MOHNs), in addition to the general electrochemical performance of MOHNs/Ketjenblack (KB) cathode-based $\mathrm{Li}-\mathrm{O}_{2}$ batteries. It has been demonstrated that the use of a simple facile template assisted growth technique is capable of producing crystalline paramagnetic MOHNs composed of many $25 \mathrm{~nm}$ mean diameter $\mathrm{Mn}_{3} \mathrm{O}_{4}$ nanoparticles, loosely agglomerated together to form the shell of a mesoporous hollow nanocage structure with a large mean diameter of $250 \mathrm{~nm}$ and a high surface area of $90.65 \mathrm{~m}^{2} \cdot \mathrm{g}^{-1}$. Moreover, the resulting MOHNs/KB cathode-based $\mathrm{Li}-\mathrm{O}_{2}$ batteries exhibit more than 50 discharge-charge cycles at a reversible restrained specific capacity of $600 \mathrm{mAh} \cdot \mathrm{g}^{-1}$ and a specific current of $400 \mathrm{~mA} \cdot \mathrm{g}^{-1}$.

This paper is extended from the previous proceedings paper [16]. It broadens the previous focus on the physical aspect of MOHNs to the physicochemical aspect of MOHNs. We thereby provide a more comprehensive evaluation and elaboration on the physicochemical properties and formation mechanism of MOHNs, as well as the electrochemical performance of MOHNs/KB cathode-based $\mathrm{Li}-\mathrm{O}_{2}$ batteries. An analysis of death batteries is also performed, in order to understand how the mesoporous hollow nanocage structure of $\mathrm{MOHNs}$ provides a pathway for better diffusion of reactants and products, how it prevents the blockage of pores from $\mathrm{Li}_{2} \mathrm{O}_{2}$, and how it improves the cyclic stability of $\mathrm{Li}-\mathrm{O}_{2}$ batteries.

The figure captions of Figures $2-5$ are added with the following statements:

Figure 2a is reproduced with permission from [16]. Copyright IEEE, 2016.

Figure $3 b$ is reproduced with permission from [16]. Copyright IEEE, 2016.

Figure 4a,d are reproduced with permission from [16]. Copyright IEEE, 2016.

Figure 5 is reproduced with permission from [16]. Copyright IEEE, 2016.

The authors regret any inconvenience or misunderstanding caused by these errors. The manuscript will be updated and the original will remain available on the article webpage. 


\section{Reference}

1. Chatterjee, A.; Or, S.W.; Cao, Y.L. Transition Metal Hollow Nanocages as Promising Cathodes for the Long-Term Cyclability of $\mathrm{Li}-\mathrm{O}_{2}$ Batteries. Nanomaterials 2018, 8, 308. [CrossRef] [PubMed] 